\title{
Erratum to: Light affects anthocyanin biosynthesis via transcriptional regulation of COP1 in the ever-red leaves of crabapple Malus cv. 'Royalty'
}

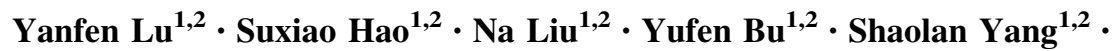
Yuncong Yao ${ }^{1,2}$

Published online: 12 July 2016

(C) Botanical Society of Sao Paulo 2016

Erratum to: Braz. J. Bot (2016) 39(2):659-667

DOI 10.1007/s40415-016-0277-8

The species name in the title and the text of the original publication should read: Malus cv. 'Royalty'.

The online version of the original article can be found under doi:10.1007/s40415-016-0277-8.

Yuncong Yao

yaoyc_20@126.com

1 Plant Science and Technology College, Beijing University of Agriculture, Beijing 102206, China

2 Beijing Collaborative Innovation Center for Ecoenvironmental Improvement with Forestry and Fruit Trees, Beijing 102206, China 